\title{
Habilidade social, relações entre campos e mudanças: a teoria do campos de ação estratégica em $A$ theory of fields
}

FLIGSTEIN, Neil; MCADAM, Doug. A theory of fields. New York: Oxford University Press, 2012.

Gustavo Conde Margarites*

\& Gabriella Rocha de Freitas**

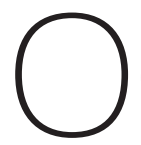
livro A theory of fields apresenta a teoria dos campos de ação estratégica (TCAE), um modelo explicativo amplo com o objetivo de entender o funcionamento da sociedade a partir da dinâmica de ordens sociais de nível meso. Embora a localização da ação social em arenas circunscritas com objetos, atores e regras próprias não seja uma originalidade, a TCAE introduz um conjunto de aportes inéditos que a ela conferem relevância no debate sobre campos. Nesta resenha, destacaremos os três principais pilares que sustentam a TCAE:

i. a ênfase na capacidade de atores sociais construírem relações de cooperação e ações coletivas dentro dos campos;

ii. a explicação do funcionamento de um campo não apenas por sua dinâmica interna, mas também pela interação com outros campos; e

iii. o enfoque nos processos de formação, de estabilização e de mudança nos campos.

O diagnóstico de fragmentação das formulações teóricas que tratam de espaços sociais delimitados foi o ponto de partida de Fligstein e McAdam. Apesar de existir uma proximidade temática entre as teorias formuladas em diversas subáreas da sociologia, a comunicação entre esses pesquisadores é dificultada pelo ambiente acadêmico que incentiva a excessiva especialização. O resultado é a pequena agregação do conhecimento sociológico. O objetivo da TCAE é superar esse obstáculo por meio da criação de uma teoria geral, capaz de estabelecer um território comum sobre o qual poderão se desenvolver os debates sobre campos que agreguem pensadores de diversas subáreas.
* Gustavo Conde Margarites é mestre em sociologia pelo Programa de Pós-Graduação em Sociologia da Universidade Federal do Rio Grande do Sul (2014), Porto Alegre, Rio Grande do Sul, Brasil. Atualmente é doutorando no mesmo programa. Possui graduação em ciências sociais pela Universidade Federa do Rio Grande do Sul (2011). <gustavo. margarites@gmail. com>.

** Gabriella Rocha de Freitas é mestre em sociologia pelo Programa de Pós-Graduação em Sociologia da Universidade Federal do Rio Grande do Sul (2014), Porto Alegre, Rio Grande do Sul, Brasil. Atualmente é doutoranda no mesmo programa. Possui graduação em ciências sociais pela Universidade Federal do Rio Grande do Sul (2011). <gabriellaf. rocha@gmail.com>. 
1. Dentre as inspirações teóricas da TCAE, a sociologia das organizações de Powell e DiMaggio (1991) e o conceito de campo de Bourdieu (2007) ocupam posição de destaque.
Boa parte da TCAE é tributária das diversas formulações teóricas sobre campos que a antecederam ${ }^{1}$. Contudo, o trabalho de Fligstein e McAdam não se limita à síntese teórica. Os elementos básicos da TCAE são elaborados a partir da incorporação dos pontos fortes de outros modelos analíticos e da identificação de limitações e formas de superá-las. O primeiro desses elementos é a definição de campo de ação estratégica. Para os autores, campos são arenas socialmente construídas onde atores com variados recursos buscam vantagens. Os campos são o espaço fundamental de operação dos atores em ações individuais e coletivas. A vida política e organizacional da sociedade se estrutura pela distribuição e articulação dos diferentes campos, que funcionam como blocos unitários básicos na construção do tecido social.

Um campo pressupõe a existência de um conjunto de atores que se relacionam entre si em função de um determinado objeto. A teia relacional de membro de um campo é estabelecida pelo compartilhamento de quatro entendimentos básicos:

i. qual é o objeto de disputa no campo;

ii. quais são os atores pertencentes ao campo e qual posição eles ocupam na hierarquia do campo (quem possui mais ou menos poder, quem são os inimigos e os aliados);

iii. quais são as regras e formas de ação consideradas legítimas;

iv. quais são os quadros interpretativos que orientam os atores do campo.

O conceito de campo de ação estratégia revela uma das principais contribuições originais da TCAE: a ênfase em atores coletivos inseridos em campos. Ao ressaltarem a importância da abordagem bourdieusiana, os autores salientam o enfoque preferencial dado pelo autor francês ao comportamento de indivíduos em campos, relegando a segundo plano a atuação de grupos nesses espaços. A TCAE oferece ferramentas capazes de preencher essa lacuna.

Para Fligstein e McAdam um campo de ação estratégica é composto por dois tipos de atores: os dominantes (incumbentes) e os desafiadores (challengers). Os dominantes são aqueles que ocupam as posições mais privilegiadas na hierarquia e, por consequência, exercem maior influência sobre os rumos do campo. É comum que as regras do campo e os entendimentos compartilhados reflitam os seus interesses. Esses atores tendem a orientar suas ações pela manutenção da ordem e pela reprodução do status quo. Os desafiadores são aqueles que apresentam menor capaci- 
dade de influência no campo. Apesar de reconhecerem a preponderância de seus adversários, suas ações estão voltadas à articulação de outras lógicas no campo, com o objetivo subverter a hierarquia e a dinâmica dominante.

A generalização da composição do campo por dominante e desafiador foi alvo de críticas por simplificar uma realidade que, por vezes, é mais complexa (Goldstone \& Useem, 2012). Ao assumir essa posição, a TCAE ignora outros arranjos e disputas que não se encaixam no binômio dominante-desafiador como, por exemplo, os conflitos entre elites. Do mesmo modo, a atribuição de um papel meramente reprodutor aos grupos dominantes inviabiliza a explicação de processos de mudança comandados por aqueles que ocupam as posições superiores na hierarquia do campo. A manutenção do status quo não se dá apenas pela reprodução das condições de estabilidade do campo.

\section{Habilidade social e ação coletiva}

A construção de coalizões de desafiadores ou de dominantes é produzida pela ação estratégica de determinados indivíduos com qualidades específicas, denominados atores habilidosos. Atores habilidosos são aqueles que possuem habilidade social, isto é, a capacidade de induzir cooperação, criando significados compartilhados e ações coletivas. O que constitui um ator habilidoso são certos atributos linguísticos, afetivos e cognitivos que facilitam a articulação e condução de demandas coletivas. Essas propriedades auxiliam na leitura de contextos e do seu público-alvo, possibilitando que o ator habilidoso enquadre a realidade de maneira atrativa para os demais, levando em consideração a multiplicidade de concepções de mundo, identidades e interesses. Em suma, o ator habilidoso é o artífice da costura da colcha de retalhos de indivíduos que conformam um ator coletivo.

A ação do ator habilidoso não depende apenas de sua capacidade de articulação. As estruturas do campo limitam o espectro de possibilidades de agência dos indivíduos. Cabe ao ator habilidoso considerar as condições estruturais que the são impostas para tomar as decisões mais proveitosas aos seus propósitos. Portanto, ao analisar a atuação de um ator habilidoso é necessário considerar também as possibilidades e os limites que decorrem do seu posicionamento hierárquico e das estruturas do campo.

A relação entre habilidade social e as coerções do campo revela o entendimento de Fligstein e McAdam sobre o binômio ação-estrutura. Nesse sentido, a TCAE se aproxima da teoria da estruturação de Anthony Giddens (2003). As estruturas são um conjunto de regras e normas formais ou informais que ordenam o funciona- 
mento do campo. Ao seguir o entendimento de Giddens, a TCAE argumenta que as estruturas têm um papel duplo: ao mesmo tempo em que podem ser um limitador, também podem ser um recurso que viabiliza a ação. Apesar da convergência sobre a dualidade entre estrutura e ação, os autores da TCAE criticam a ausência de uma concepção sobre a arena social na teoria da estruturação. Argumentam que a ausência de um locus da estruturação deixaria a teoria vaga e excessivamente abstrata. Mesmo com essa restrição, a influência da sociologia de Giddens é fundamental para a TCAE construir uma articulação entre estruturas do campo e ação estratégica que se afasta do voluntarismo do individualismo metodológico e do determinismo do estrutural-funcionalismo.

\section{Relações entre campos}

A atenção dedicada ao ambiente externo, especialmente na relação entre campos, é o segundo grande diferencial da TCAE. Em contraste com a abordagem de Bourdieu, que enfoca majoritariamente em sua autonomia e na dinâmica interna dos campos, Fligstein e McAdam afirmam que os campos constituem relações entre si, compondo uma rede interdependente. O surgimento, a estabilização e a transformação de um campo depende dos tipos de vinculação que este estabelece com os demais.

A interdependência entre campos é vital para a caracterização de Estado feita pela TCAE. Considera-se que o Estado é formado por um conjunto de campos de ação estratégica articulados de maneira sistêmica. Isso significa que os preceitos gerais da TCAE também se aplicam no âmbito estatal. A diferença está na autoridade que os campos do Estado apresentam para impor regras de funcionamento aos campos não estatais. O Estado regula a expansão e delimitação de novos espaços sociais, sendo muitas vezes o fiel da balança no momento de formalização de regras e de estabilização de campos recém-formados.

Apesar da autoridade estatal peculiar, a relação entre campos do Estado e não estatais não é unidirecional. É comum que a ação estatal seja reativa às iniciativas da sociedade em criar novos espaços sociais. A ampliação de direitos pode ser um exemplo desse processo: a sociedade se organiza com a finalidade de ter a sua demanda pela expansão de um determinado direito atendida, criando, assim, um campo não estatal. O Estado, então, identifica a necessidade de responder às reivindicações dessa nova arena social e forma um campo estatal com essa finalidade. O caminho inverso também pode ser tomado. A criação de novas leis que modifiquem a extensão dos direitos ou a estruturação de um novo campo estatal pode induzir à criação de um campo não estatal relacionado ao tema. 
Ao tratar da interação entre campos estatais e não estatais, a TCAE destaca a centralidade da relação Estado e sociedade na criação de contextos de estabilização ou de mudança. Contudo, as fronteiras entre as duas esferas são apresentadas de maneira estanque. Diversas abordagens na análise de políticas públicas têm salientado como, em muitas situações, essa separação não é tão clara. A literatura de redes e comunidades de políticas públicas estuda os processos de produção setorizada de políticas em espaços onde atores estatais, societais e de mercado se agregam em torno de determinado tema. A característica básica desses campos é a fluidez entre Estado e sociedade (Jordan, 1990). A TCAE é omissa sobre a possibilidade do multipertencimento de um ator a diversos campos e não discute de que maneira o trânsito desses indivíduos pode afetar as relações entre os campos.

\section{Estabilidade e mudanças no campo}

Para a elaboração do seu entendimento sobre mudança e estabilidade nos campos, a TCAE recorre ao debate entre o modelo do equilíbrio pontuado (externalistas) (Baumgartner \& Jones, 1993) e os neoinstitucionalistas (internalistas) (Streeck \& Thelen, 2005). De acordo com o modelo do equilíbrio pontuado, campos são marcados pela estabilidade constante interrompida por momentos curtos e intensos de transformações provocados por eventos externos que colocam em xeque os fundamentos desses espaços. Os neoinstitucionalistas criticam essa perspectiva, afirmando que equilíbrio pontuado ignora a sutileza da dinâmica institucional e a produção ativa da estabilidade por meio de disputas constantes entre os integrantes de um campo. O resultado dessas contendas discretas são mudanças incrementais que se acumulam com o passar do tempo e que, por vezes, criam condições para transformações de maiores proporções. Fligstein e McAdam consideram que as duas posições não são excludentes e podem ser equalizadas. A diferença entre os tipos de transformações está em distintos processos desencadeadores. Mudanças em campos estáveis normalmente são resultados das dinâmicas institucionais incrementais, enquanto o surgimento ou o colapso de campos guardam maior relação com eventos externos.

O diferencial da TCAE nesse aspecto é a tentativa de articular disputas cotidianas e choques exógenos na explicação de grandes rupturas. Mudanças incrementais são o resultado da constante disputa por posição entre dominantes e desafiadores que, ao longo do tempo, pode alterar profundamente os entendimentos básicos que sustentam um campo. Quando ocorrem eventos exógenos - sejam eles macroeventos que disseminam uma sensação generalizada de crise ou transformações em campos próximos - os processos latentes de mudança podem irromper, alterando radicalmente os fundamentos do campo. 
A participação dos atores habilidosos também é importante para os processos de mudança e estabilização do campo. Atores habilidosos podem assumir o papel de empreendedores institucionais, identificando janelas de oportunidades e organizando os emergentes em prol do engendramento de mudanças. Por outro lado, esses atores podem ser responsáveis por construir e assegurar o compartilhamento por parte de seus integrantes de uma nova ordem que estabilize os campos instáveis ou recém-formados. Nesse ponto, mais uma vez emerge a dualidade da estrutura presente na TCAE. As condições internas e externas dos campos podem limitar as ações que acarretem grandes mudanças, mas também podem ser utilizadas como recurso para o desencadeamento de processos de transformação. Ademais, a conformação, consolidação e reprodução das novas regras do campo são fabricadas pela atuação de seus membros, evidenciado a presença da retroalimentação entre estrutura e ação.

A TCAE apresenta avanços em relação às demais abordagens sobre espaços sociais de nível meso. Nesta resenha, argumentamos que foram três as principais contribuições da TCAE para o debate sobre campos.

i. As categorias de habilidade social e de ator habilidoso auxiliam na explicação da formação de relações de cooperação e de atores coletivos, conferindo importância aos indivíduos sem cair nas armadilhas do voluntarismo ou do determinismo estrutural.

ii. Ao reputar que a explicação do funcionamento dos campos deve considerar a relação com o ambiente externo formado por outros campos, a TCAE complexifica interpretações que reduzem seu entendimento exclusivamente a dinâmicas internas desses espaços.

iii. A ênfase excessiva na reprodução e o reduzido desenvolvimento de perspectivas acerca da mudança sempre foram entraves para as teorias do campo.

Ao equacionarem as posições externalistas e internalistas, Fligstein e McAdam elaboraram um modelo explicativo capaz de abarcar a diversidade e complexidade dos processos de transformação.

Deve-se reconhecer que a TCAE dá um passo importante na construção de um substrato comum no qual as subáreas da sociologia que tratam da ação social localizadas em campos possam se comunicar. Ao identificar limitações e articular elementos de 
diversas perspectivas, construindo uma teoria coerente, Fligstein e McAdam estabelecem um ponto de partida para a construção de uma agenda comum de pesquisa sobre a dinâmica relacional que opera dentro dos campos de ação estratégica e o seu relacionamento com o ambiente externo.

\section{Referências}

BAUMGARTNER, Frank; JONES, Bryan. Agendas and instability in American politics. Chicago (IL): University of Chicago Press, 1993.

BOURDIEU, Pierre. A distinção: crítica social do julgamento. Porto Alegre: Zouk, 2007.

GIDDENS, Anthony. A constituição da sociedade. São Paulo: Martins Fontes, 2003.

GOLDSTONE, Jack; USEEM, Bert. Putting values and institutions back into the theory of strategic action field. Sociological Theory, v. 30, n. 1, p. 37-47, Mar. 2012.

JORDAN, Grant. Sub-governments, policy communities and network: refilling the old bottles? Journal of Theoretical Politics, v. 2, n. 3, p. 319-338, 1990.

POWELL, Walter; DIMAGGIO, Paul. Introduction. In: POWELL, Walter; DIMAGGIO, Paul (Eds.). The new institutionalism in organizational analysis, p. 1-38. Chicago: University of Chicago Press, 1991.

STREECK, Wolfgang; THELEN, Kathleen. Beyond continuity: institutional change in advanced political economies. Oxford (UK): Oxford University Press, 2005. 